\title{
OS CORPOS DAS DANÇAS NO CURRÍCULO CULTURAL DE EDUCAÇÃO FÍSICA
}

\author{
ADRIANA DE FARIA GEHRES ${ }^{1}$ \\ ORCID: https://orcid.org/0000-0003-1274-2514 \\ PEDRO XAVIER RUSSO BONETTO ${ }^{2}$ \\ ORCID: https://orcid.org/0000-0002-3194-1423
}

MARCOS GARCIA NEIRA ${ }^{3}$

ORCID: https://orcid.org/0000-0003-1054-8224

\begin{abstract}
RESUMO: O currículo cultural de Educação Física é uma proposta inspirada nos pressupostos teóricos dos estudos culturais, do multiculturalismo crítico, do pós-estruturalismo e do pós-colonialismo (NEIRA, 2019), e, desde 2004, vem sendo realizada nas escolas de Educação Básica pelos professores e professoras do Grupo de Pesquisas em Educação Física Escolar (GPEF) da Faculdade de Educação da Universidade de São Paulo e continuamente reelaborada. Para o GPEF, as práticas corporais são textos culturais produzidos pela linguagem corporal e discursiva. O registro no formato de relatos de experiência é um dos procedimentos adotados pelo grupo. Nosso objetivo foi cartografar (DELEUZE; GUATTARI, 1996) os relatos das experiências com danças, entendendo os corpos das danças como os conteúdos propostos pelo currículo cultural. Para tanto, foram analisados 15 documentos, identificados num universo de 113 relatos divulgados no site institucional do GPEF. Nossa cartografia produziu vontades de compor, multiplicar e intensificar que acionaram políticas públicas, currículo cultural, corpos e danças.
\end{abstract}

Palavras-chave: Educação Física, currículo cultural, corpo, dança.

\section{THE BODIES OF DANCES IN THE CULTURAL CURRICULUM OF PHYSICAL EDUCATION}

\begin{abstract}
The cultural curriculum of Physical Education is a proposal inspired by the theoretical presuppositions of cultural studies, critical multiculturalism, post-structuralism and post-colonialism (NEIRA, 2019), and, since 2004, it has been fulfilled in the Basic Education schools by teachers of the Physical Education Research Group (GPEF) of the School of Education of the University of São Paulo and continuously reworked. For GPEF, corporal practices are cultural texts produced by body language and discourse. Recording in the format of experience reports is one of the procedures adopted by the group. Our objective was to cartograph (DELEUZE, GUATTARI, 1996) the reports of the experiences with dances, understanding the bodies of the dances as the contents proposed by the cultural curriculum. For this purpose, 15 documents were analyzed, identified in a universe of 113 reports published on the institutional website of GPEF. Our cartography produced the wills of composing, multiplying and intensifying that triggered public policies, cultural curriculum, bodies and dances.
\end{abstract}

Keywords: Physical Education, cultural curriculum, body, dance.

\footnotetext{
${ }^{1}$ Universidade de Pernambuco (UPE). Recife, PE, Brasil. < adriana.gehres@upe.br >

${ }^{2}$ Faculdade Flamingo (FaFla). São Paulo, SP, Brasil. <psorpedro@yahoo.com.br>

${ }^{3}$ Universidade de São Paulo (USP). São Paulo, SP, Brasil. <mgneira@usp.br> 


\section{LOS CUERPOS DE DANZA EN EL CURRÍCULO DE EDUCACIÓN FÍSICA CULTURAL}

RESUMEN: El currículum cultural de Educación Física es una propuesta inspirada en los supuestos teóricos de los estudios culturales, el multiculturalismo crítico, el postestructuralismo y el poscolonialismo (NEIRA, 2019), y, desde 2004, los maestros y profesores del Grupo de Investigación en Educación Física Escolar (GPEF) de la Facultad de Educación de la Universidad de São Paulo lo llevan a cabo en las escuelas de Educación Básica y lo reelaboran continuamente. Para GPEF, las prácticas corporales son textos culturales producidos por el cuerpo y el lenguaje discursivo. El registro en forma de informes de experiencia es uno de los procedimientos adoptados por el grupo. Nuestro objetivo fue mapear (DELEUZE; GUATTARI, 1996) los informes de las experiencias con las danzas, entendiendo los cuerpos de las danzas como los contenidos propuestos por el currículum cultural. Con este fin, se analizaron 15 documentos, identificados en un universo de 113 informes publicados en el sitio web institucional de GPEF. Nuestra cartografía produjo la voluntad de componer, multiplicar e intensificar las políticas públicas, el currículum cultural, los cuerpos y los bailes.

Palabras clave: Educación Física, currículum cultural, cuerpo, danza.

\section{INTRODUÇÃO}

Quando nos debruçamos sobre o campo dos estudos curriculares em Educação Física, genericamente, observamos uma larga produção acerca das propostas pedagógicas sistematizadas desde os anos 1980 e que têm se instalado com base em diferentes pressupostos, em geral aqui identificados como críticos ou acríticos, considerando-se a relação escola e sociedade (SAVIANI, 1983): críticosuperadora (SOARES et al., 1992) e crítico-emancipatória (KUNZ, 1994); e, desenvolvimentista (TANI et al., 1988); educação para a saúde (GUEDES, 1995); e psicomotora (FREIRE, 1989).

Organizadas como parte das disputas pela identificação de um objeto de estudo para a Educação Física que divergisse dos paradigmas da aptidão física, as propostas que situavam a educação no campo da transformação social (críticas) voltaram-se para o estudo da Educação Física como cultura.

Como bem afirmou Bracht (2011), o centro da discussão no campo da Educação Física ficou encapsulado nas disputas entre os objetos de estudo que miravam a cultura corporal, cultura de movimento e cultura corporal de movimento, no campo das propostas de viés crítico, com todas assumindo um referencial centrado na cultura. Na priorização do corpo, do movimento ou de ambos, diferenciavam-se os pressupostos epistêmico-metodológicos para a prática pedagógica da Educação Física escolar.

Nesse ambiente de debates intensos, o início do século XXI viu surgir, no campo da Educação Física, uma proposta que incorporou outras formas de análise do social, da educação, da cultura e do currículo, genericamente denominadas de teorias pós-críticas (LOPES, 2013). ${ }^{4} \mathrm{O}$ currículo cultural em

\footnotetext{
${ }^{4}$ Lopes (2013) informa que existem registros pós-estruturais, pós-coloniais, pós-modernos, pós-fundacionais e pós-marxistas que são denominados, genericamente, como estudos pós-críticos em currículo. É nesse ambiente que localizamos as propostas do GPEF.
} 
Educação Física organizou-se, inicialmente, nos estudos de Neira e Nunes (2006), ${ }^{5}$ para imbricar-se e alimentar-se nas práticas de professores das redes públicas e privadas da Grande São Paulo, por meio das atividades do Grupo de Pesquisa em Educação Física Escolar (GPEF) da Faculdade de Educação da Universidade de São Paulo (FEUSP).

Resumidamente, Neira e Nunes (2006, 2009), Neira (2011, 2018, 2019) e também o GPEF partiram inicialmente dos estudos culturais e do multiculturalismo crítico para desestabilizar as posturas críticas e acríticas em Educação Física, sobretudo explodindo com a noção de identidade única, fixa e hegemônica que caracterizara as propostas da Educação Física até então, com intuito de dar a ver as culturas não hegemônicas na escola, ampliando a discussão para além da classe social e incluindo os marcadores sociais de gênero, raça, etnia e religião que perpassam as práticas corporais, o que contribuiu para o surgimento de outras formas de promover intervenções didáticas. Contudo, com Bonetto (2016), entre outros, podemos afirmar que, atualmente, os campos de inspiração do currículo cultural em Educação Física têm se expandido para outros ambientes teóricos, sobretudo aqueles denominados, genericamente, de pós-estruturalistas ${ }^{6}$.

Nesse processo de aprofundamento, aproximações, questionamentos recorrentes de teorias e práticas moventes, Neira e Nunes (2011) e Neira (2016; 2019) propõem conceitos e metáforas (escritacurrículo, escrita-artista, metáfora da capoeira), princípios ético-políticos (reconhecimento da cultura da comunidade, justiça curricular, evitar o daltonismo cultural, descolonização do currículo, ancoragem social dos conhecimentos) e encaminhamentos pedagógicos (mapeamento, leitura das práticas corporais, vivências, ressignificação, aprofundamento, ampliação, registro e avaliação) para a efetivação do currículo cultural. Entretanto, essas proposições vão se transformando com os fazeres dos membros do GPEF e suas práticas de relatos de experiências e discussões.

Para o currículo cultural em Educação Física, na trilha dos Estudos Culturais, as práticas corporais são textos culturais, os quais

[...] são compreendidos como produções sociais, locais e práticas em que o significado é negociado, traduzido, fixado e ressignificado. Ou seja, nos textos da cultura as identidades e as diferenças são produzidas, representadas e marcadas. É na cultura, na luta pela significação, que nasce a desigualdade social (NEIRA, 2011, p. 28).

E, numa produção mais recente, apontam que

[...] as práticas corporais, enquanto textos culturais, estão impregnadas de marcadores sociais de etnia, religião, classe, gênero, entre outros, podendo ser lidas e produzidas de diversas maneiras,

\footnotetext{
${ }^{5}$ Embora as produções dos autores tenham se iniciado a partir de 2006, os documentos analisados neste artigo foram produzidos mais recentemente pelos professores e professoras que assumem colocar em ação a perspectiva pós-crítica, ocasião em que as produções começam a inspirar-se no pós-estruturalismo para aprofundar as discussões sobre linguagem e produção das diferenças.

${ }^{6}$ Sobre o currículo cultural em Educação Física, Bonetto (2016) vasculhou seus pressupostos, embrulhou e desembrulhou suas produções, conceitos, princípios ético-políticos e procedimentos, em ações ora de criação, ora de verificação, fazendo-se acompanhar pela geofilosofia de Deleuze e Guattari. Nesse processo, o autor debruçou-se sobre o conceito de escrita-currículo e, ao escrutiná-lo, compõe-no em: historicidade, assinatura, planos ou campos de imanência, elementos ou componentes, multiplicidades, personagens conceituais, traços de intensidade e objetividade.
} 
dependendo da posição que o sujeito ocupa no emaranhado social (COSTA; NEIRA, 2016, p. 43).

Enquanto isso, o corpo

[...] não é somente objeto de contenção, controle e disciplinamento, mas também de expressividade. O corpo é a forma que o sujeito tem de manifestar-se e agir no mundo - e, sob esse aspecto, o movimento é a expressão das emoções e pensamentos, é uma linguagem. (COSTA; NEIRA, 2016, p. 41).

As asserções supra traduzem a especificidade do currículo cultural em Educação Física, como área de atuação e conhecimento, na produção das práticas corporais como textos culturais, identidades, diferenças e poder. Práticas corporais, corpo e linguagem são intensidades na ação do currículo cultural para desestabilizar regimes de verdade no âmbito da Educação Física escolar.

Por outro lado, as discussões sobre o corpo e a linguagem corporal, na Educação Física, no Brasil, encontram-se, entre outros, ancoradas nos debates sobre a fenomenologia. Almeida, Bracht e Ghidetti (2013) localizam a questão sobre a fenomenologia na Educação Física no Brasil, a partir dos estudos de cinco autores (Terezinha Petrucia da Nóbrega, Silvino Santin, Manuel Sérgio, Wagner Wey Moreira, Elenor Kunz), destacando o trabalho da primeira e do último, como aqueles que, na área da Educação Física, mais aprofundam o estudo da fenomenologia no Brasil. Acerca do corpo e da noção de corporeidade na obra de Merleau Ponty, os autores apontam a aproximação de Nóbrega com os estudos das ciências cognitivas como um elemento diferenciador e ampliador da discussão a respeito do corpo na Educação Física. No entanto, os autores ressaltam alguns limites nos trabalhos relativamente à fenomenologia na Educação Física no Brasil e, um deles, é explicitado a partir das críticas de Betti (2006) sobre a ausência de discussão, na fenomenologia de Merleau Ponty, de questões relacionadas às finalidades e fins da sua fenomenologia, um resíduo de não sentido, nas palavras do autor, ou uma ausência de axiologia, tão cara à educação, à escola e ao currículo.

Greiner $(2008,2010)$ demonstra como a fenomenologia foi uma metodologia importante para os estudos sobre o corpo na sua relação com o outro (ser) e com a experiência (ser no mundo). Nesse caminho, assinala que as fenomenologias de Merleau Ponty e de Heidegger diferem da fenomenologia transcendental de Husserl. E, no aprofundamento dos seus estudos acerca da relação do corpo com a cognição e a política, Greiner (2010) também realça os estudos no campo das ciências cognitivas que vão se apartar do corpo da fenomenologia, no entendimento da percepção não mais como algo que acontece em nós, mas como algo que fazemos. Perceber é agir e agir é agir corporalmente. A percepção/ação já é um modo de pensar sobre o mundo. "O conteúdo da experiência e o conteúdo do pensamento são os mesmos" (GREINER, 2010, p. 76).

Apropriando-nos ainda mais da discussão sobre a linguagem numa perspectiva pragmática, salientamos que, para Deleuze e Guattari (1995a), a expressão e o conteúdo têm formas próprias, a forma 
conteúdo ou lição dos "corpos"ᄁ e a forma expressão, a lição dos signos, que agem uma sobre a outra. A função linguagem, assim entendida, opera por meio da atribuição dos expressos, os enunciados, sobre os conteúdos. Portanto, os expressos não representam, comunicam ou informam os conteúdos, porque há total independência entre eles, apesar da presença de uma relação de reciprocidade, mas o que assistimos é a uma intervenção incessante de um sobre o outro (perceber é agir, conceituar é agir), na transmissão constante de palavras de ordem.

A função-linguagem é transmissão de palavras de ordem, e as palavras de ordem remetem aos agenciamentos, como estes remetem às transformações incorpóreas que constituem as variáveis da função. A linguística não é nada fora da pragmática (semiótica ou política) que define a efetuação da condição da linguagem e o uso dos elementos da língua (DELEUZE; GUATTARI, 1995a, p. 20).

Nesse ambiente, entendemos que, no currículo cultural, a linguagem corporal, práticas corporais e seus corpos destacam-se como a própria ação política e intencional, afastando-se das experiências perceptivas sensíveis, ainda que encarnadas no mundo, do corpo da fenomenologia.

As práticas corporais, no currículo cultural, acionam, todo o tempo, disputas de significações culturais e sociais e os procedimentos didáticos operam na chave da problematização e da desconstrução das práticas corporais e discursivas que produzem as diferenças para o combate à fixação de significados e para a produção de mais diferença.

O currículo cultural, na atuação do GPEF, aponta para uma produção em cascata de jogos de linguagem (conteúdos e expressos) em aulas, relatos, dissertações, teses, livros, palestras, discussões e iniciativas de formação continuada que agem sobre o próprio currículo cultural e suas práticas, desestabilizando-o constantemente (GEHRES; NEIRA, 2020, p. 36).

Os autores veem emergir um fazer em que conteúdos e expressos abandonam a correspondência ou a representação de um sobre o outro, para atuar na produção de "palavras de ordem", ou as transformações incorpóreas que criam diferentes lugares de fala e hierarquias de poder.

As práticas corporais agem sobre os conteúdos (corpos sociais) não para informá-los/comunicálos/representá-los, mas para produzi-los. As práticas corporais, como lição dos signos, são a função linguagem transmitindo palavras de ordem, operando como agenciamentos na criação de transformações incorpóreas aos corpos. Nesse sentido, os marcadores sociais estão nos próprios corpos propostos pelas práticas, as quais atuam como agenciamentos. Ao produzirem corpos nas aulas culturalmente orientadas, em suas intensidades e multiplicidades, conteúdos (corpos periféricos, menores, piores) e expressos (práticas corporais negras, indígenas, urbanas, infantis) exercitam a função linguagem das práticas corporais. Tomemos o caso das danças...

As danças, como linguagem corporal, ao serem dançadas, partilhadas, performadas, tematizadas como expressos, emitem palavras de ordem que remetem a agenciamentos que provocarão

\footnotetext{
${ }^{7}$ Nesse momento do texto, os autores estão se referindo a uma primeira filosofia da linguagem, por eles identificada entre os estoicos. Segundo Deleuze e Guattari (1995b), os estoicos dão à palavra corpo o sentido de ser todo o conteúdo formado. Educação em Revista | Belo Horizonte|v.36|e219772|2020
} 
transformações incorpóreas aos corpos que dançam, acionando-os como corpos negros, trans, jovens, idosos, infantis, deficientes etc., sendo esse processo a pragmática semiótica e política proposta pelo currículo cultural. "Há que se promover a interação e interdependência entre os saberes de todos os tipos (hegemônicos, contra-hegemônicos, legitimados, marginalizados) para que o conhecimento seja compreendido como intervenção, e não como representação" (NEIRA, 2019, p. 97).

Portanto, o conhecimento no currículo cultural é o processo incessante de intervir na produção de corpos/conhecimento. Mas como o fazem? É comum encontrarmos nas práticas do currículo cultural, sobretudo naquelas reveladas pelos relatos de experiência, ${ }^{8}$ uma descrição das intervenções pedagógicas influenciadas pelos princípios ético-políticos curriculares, metáforas e procedimentos didáticos, inferidos por Neira e Nunes $(2011)$ e Neira $(2018,2019)$ em face dos estudos das práticas pedagógicas. Contudo, uma apresentação mais explícita acerca dos corpos produzidos pelo currículo cultural não foi identificada no amplo material do GPEF. Eis o mote deste artigo, que pretendeu cartografar os corpos (conteúdos) do currículo cultural considerando as descrições expostas nos relatos de experiência elaborados pelos professores e professoras do GPEF que cotidianamente dão vida a essa proposta singular no campo da Educação Física Escolar.

E, para essa cartografia/atualização do currículo cultural, aprofundamos na composição de corpos políticos interventivos, ou seja, aqueles que têm na reciprocidade entre conteúdo e expressão a sua ação, com intuito de nos aproximarmos de uma pragmática política que evidencia a função intensiva/interventiva do corpo e das práticas corporais, mais especificamente das danças como linguagem na produção de palavras de ordem (DELEUZE; GUATTARI, 1995b).

Para tanto, tomamos os relatos de experiência referentes às danças (expressos) produzidos pelos membros do GPEF como documentos a serem cartografados, considerando que os relatos que narram tematizações das danças ocupam o currículo cultural com pertinência e relevância, além das possibilidades oferecidas pelas danças ao tomarem o próprio corpo como o seu lugar de produção social, artística e cultural (GREINER, 2008).

\section{MATERIAIS E MÉTODO}

Mas o que é cartografar? Cartografar é um objetivo de pesquisa ou é o próprio procedimento da pesquisa? Bem, cabe-nos aqui retornar ao ambiente teórico-metodológico com o qual dialogamos para produzir nossa questão/objetivo, quando a pragmática deleuze-guattariana, que, como metodologia ou uma não epistemologia, propõe-se a vir a ser, cochicha:

Todo centro de poder tem efetivamente estes três aspectos ou estas três zonas: 1) sua zona de
potência, relacionada com os segmentos de uma linha sólida dura; 2) sua zona de
indiscernibilidade, relacionada com sua difusão num tecido microfísico; 3) sua zona de
impotência, relacionada com os fluxos e quanta que ele só consegue converter, e não controlar
nem determinar. [...] O estudo dos perigos em cada linha é o objeto da pragmática ou da

\footnotetext{
${ }^{8}$ Os professores e professoras que atuam conforme a proposta registram suas experiências no formato de relatos. Os documentos encontram-se publicados no site institucional do grupo: www.gpef.fe.usp.br.

Educação em Revista | Belo Horizonte|v.36|e219772|2020
} 
esquizoanálise, visto que ela não se propõe a representar, interpretar nem simbolizar, mas apenas a fazer mapas e traçar linhas, marcando suas misturas tanto quanto suas distinções (DELEUZE; GUATTARI, 1996, p. 99-100).

Na produção dessa filosofia, Deleuze e Guattari (1996) seguiram estudando os perigos dessas linhas e inventando conceitos, a tarefa da filosofia, como ato, performance, ação. Cartografar é, então, a própria pesquisa. Partindo a cartografia da noção de ação e implicação, compreendemos que esta se estabelece no "meio" entre sujeito e objeto, dicotomia e separação que esse tipo de pesquisa busca superar não como conflito desvelado pelos pesquisadores para a geração de consciência e atuação, mas, como afirma Romagnoli (2014, p. 46-47), no entendimento de que “[...] a realidade é abordada por imanência e exterioridade, e o 'meio' emerge como a dimensão que sustenta os devires, que vai produzir agenciamentos fazendo eclodir o novo".

Assim, uma das tarefas do cartógrafo é provocar e manter a consistência de agenciamentos maquínicos, ou seja, fomentar o plano das forças inventivas e conectivas.

Nossa cartografia se estabeleceu aqui, nesse "entre" coletivo de vontades de verdade que se firmam como fluxos. A tarefa da pesquisa não foi descrever, representar ou interpretar o que se apresenta nos relatos de experiência, mas fazer mover o que já é movente. O processo de cartografar os relatos sobre as danças no currículo cultural intensificou ambientes corporais (conteúdos) da dança (expressos) que lá estavam.

Cartografaram-se todos os relatos de experiências em que as danças foram tematizadas. Samba, frevo, maracatu, sertanejo e funk, cada um com dois relatos. Dois relatos referiam-se à cultura hip-hop, embora apenas um deles tenha se dedicado à dança. Um dos relatos trabalhou com danças eletrônicas, outro, danças de todo o Brasil, e foi identificado também um relato sobre o balé. As experiências narradas foram empreendidas em escolas de ensino fundamental, prioritariamente públicas, ainda que um dos relatos seja de uma escola privada; e um dos relatos foi desenvolvido em uma escola técnica de ensino médio. Houve experiências que ocorreram no ensino regular e uma delas na educação de jovens e adultos. O intervalo temporal dos relatos avaliados vai de 2009 a 2017.

\section{RESULTADOS E DISCUSSÃO}

A convivência com os relatos de experiência de dança do GPEF, nos atos de ler e reler, permitiu indicar linhas, registrando suas combinações e diferenças. Nesse processo, corpos a compor entre os projetos institucionais e as personagens comunitárias; corpos a multiplicar entre esporte, brincadeira, ginástica, dança, masculino, feminino, trans, urbano, rural, profano, sagrado, negro, índio; corpos a intensificar entre o tambor, o smartphone e o alto-falante. 


\section{Compor entre os projetos institucionais e as personagens comunitárias}

Grande parte dos relatos de experiência com as danças localiza-se nas questões postas pela legislação e pela escola no seu movimento em direção à comunidade nos inúmeros projetos ${ }^{9}$ que atravessaram as escolas naqueles anos: Trabalho Colaborativo Autoral (TCA), Plano Especial de Ação (PEA), Projeto Pedagógico Curricular (PPC) e Plano Curricular (PC).

Projetos escolares e legislação que propõem o trânsito entre a comunidade e a escola em vários sentidos, mas principalmente para a visibilização da diversidade cultural vivida. Esses projetos abrem passagem entre os corpos dançantes da escola e de fora dela em ações, personagens e atuações plurais.

Lima (2016) indica que a dança foi escolhida por estar presente no PC daquele ano letivo e, ao longo do relato, descreve duas tentativas não concretizadas de trazer pessoas da comunidade para estarem com os/as estudantes. Para finalizar o projeto e deslizar entre o PC e a comunidade, os/as estudantes investigam com pessoas da própria escola, funcionários, outros professores e professoras e estudantes sobre a dança tematizada.

Colombero (2014) aproveita a parceria que a escola estabelece com o Sarau do Binho, no âmbito do TCA, como um projeto interdisciplinar, e conta com a colaboração da mãe de uma aluna para dançar e promover as vivências com o samba de roda.

Martins (2009) e Nascimento (2013) descrevem seus trabalhos como um desdobramento ou em atenção ao PEA. A primeira traz para dentro da escola as aulas de uma professora de outra escola e viceversa, mediante a troca de filmagens das aulas em ambas as escolas, e, na mostra final, grupos da comunidade percorrem e participam do evento. Posteriormente, esses grupos solicitam utilizar a escola para seus próprios ensaios.

Fogaça (2014) e Santos Júnior (2015) inscrevem seus projetos a partir da legislação sobre a abordagem da cultura afro-brasileira e africana. ${ }^{10}$ Santos Júnior (2015) conta com a participação nas aulas de um aluno que havia visitado o Estado de Pernambuco, lugar em que localizamos, mais explicitamente, a dança do passo, o frevo.

Neves $(2011,2015,2017)$, em seus três relatos, parte de projetos da escola (PEA e sua relação com o grêmio da escola, projeto para todos os componentes), e neles convida pessoas da comunidade a participar das atividades. Em dois dos relatos, faz-se acompanhar também de outros professores da escola e no outro divide a condução dos encontros com um ex-aluno, que chamou para uma palestra. $\mathrm{O}$ exaluno solicitou permanecer nas aulas e assim ocorreu, enquanto duas alunas estrangeiras receberam o

\footnotetext{
${ }_{9}$ A depender da unidade escolar e da rede à qual pertence, a nomenclatura adotada diverge. O TCA consiste na realização de uma pesquisa pelos estudantes do último ciclo do ensino fundamental, denominado "autoral", a partir de um problema identificado na comunidade. A pesquisa conta com orientação dos professores e é apresentada publicamente. O PEA consiste num trabalho coletivo por segmento ou ano escolar, com tempo semanal reservado para planejamento e avaliação. O PPC e o PC referem-se aos projetos pedagógicos das unidades.

${ }^{10}$ A Lei 10.639/2003 estabelece a obrigatoriedade do ensino de "história e cultura afro-brasileira e africana" em algumas disciplinas que fazem parte das grades curriculares dos ensinos fundamental e médio. Também estabelece o dia 20 de novembro como o Dia da Consciência Negra.
} 
convite para demonstrar como era aquela prática corporal em seu país, e depois também passaram a frequentar as aulas do professor.

Portanto, as danças experimentadas, práticas corporais entendidas como expressos, lição dos signos, compõem corpos/conhecimentos comunitários que povoam a escola, os quais, se assim não fosse, seriam despotencializados pela burocracia (realizar os projetos institucionais apenas para cumprir metas) ou pela invisibilidade a que são lançados/as muitas vezes funcionários/as, alunos/as e exalunos/as menos "academicamente" dotados e os pais e as mães que não se deslocam à escola, mas que são vidas vividas a sol e chuva, cotidianamente, para além das escolas.

Não há como negar o intenso diálogo com a cultura comunitária e sua ressonância na valorização das significações (danças e corpos) culturais locais. Seguindo os rumos das políticas públicas que reconhecem a força presente no território das escolas consubstanciadas no TCA e no PEA ou, mesmo, nos princípios ético-políticos que mobilizam professores e professoras que atuam em consonância com o currículo cultural (NEIRA, 2019), têm-se, simultaneamente, o reconhecimento da cultura corporal da comunidade e a ancoragem social dos conhecimentos. A vontade de compor acontece no "entre" as linhas de força de aglutinação e controle das políticas públicas e os sotaques e gingados das personagens comunitárias, transcriando danças e corpos.

\section{Multiplicar entre os/as professores/as e os/as alunos/as e os corpos e as danças}

Quase na sua totalidade, os relatos de experiência cujos/as professores/as se deixam influenciar pelos princípios ético-políticos do currículo cultural, sobretudo a justiça curricular e a descolonização do currículo (NEIRA; NUNES, 2011), optaram pela dança em razão de sua ausência ou circunjacência em relação às demais práticas corporais (SANTOS JÚNIOR, 2015; SANTOS, 2013; MARTINS, 2013; AGUIAR, 2009; NEVES, 2011; QUARESMA, 2015, PORTAPILA, 2013), e/ou por sua presença como entretenimento/recreativa/festiva nas escolas (SANTOS JÚNIOR, 2015; NEVES, 2015), e/ou por sua manifestação tão evidente nos corpos musicais dos corredores, portões e recreios das escolas (NASCIMENTO, 2013; AGUIAR, 2009; MARTINS, 2009; QUARESMA, 2015). Dada a partida, os relatos que tematizaram a dança em sua situação periférica (ser minoritária como tema abordado no currículo) ou subalterna (ser uma cultura dos estudantes ou simplesmente diversão) na Educação Física e nas escolas vão reverberando em sons, cores, empurrões e resistências dos/as alunos/as, da escola, das mães, dos funcionários para a criação de outras periferias e centros?

Joaquim (2016) inicia suas experiências com o maracatu a partir de um comentário de um aluno: Dona, a senhora é macumbeira? A negritude do maracatu assim se faz tematizada e problematizada em músicas, movimentos, roupas e filmes, na produção de corpos que tocam e dançam o maracatu. $\mathrm{O}$ preconceito contra a religiosidade afrodescendente, motivadora do trabalho, afasta-se durante o seu desenvolvimento, mas, sem que eles ou nós percebamos, vem à tona na oscilação das saias, alfaias e 
corpos, ainda que tenha sido deslocada de sua centralidade, no jogo de espelhos e contraespelhos, que é o processo de se arriscar nas linhas de poder que produzem centros e periferias.

Neves (2017), num movimento semelhante com alunos da educação de jovens e adultos, entretece linhas e formas que aprofundam a vinda e a vida do negro no Brasil a partir de uma historiografia descentrada da versão branca e oficial da escravidão. Os batuques, as danças e os cantos do cortejo transfiguram-se em cultura para a aluna que constituía o maracatu como macumba ou coisas do demônio. O deslocamento da dança, música e religiosidade para a cultura movimenta o jogo de centramento e descentramento realizado na prática do currículo cultural. No movimento entre sagrado e profano, que retorna ao sagrado de Joaquim (2016) e Neves (2017), vão se produzindo as camadas dos corpos/conhecimento.

Lima (2016), ao introduzir, inicialmente, a dança (expresso) como tema, no 2. ${ }^{\circ}$ ano do ensino médio de uma escola técnica, descreve as discussões sobre as religiosidades indígena e negra e a sensualidade. Posteriormente, seleciona o funk, e os questionamentos acerca da apologia do sexo emergem. Discutem-se sexo e apologia com meninas e meninos, a partir das letras do funk. Realizam movimentos e alguns relatam que "conseguem", outros não, e, assim, o projeto vai chegando ao seu final. Ao tematizar a dança em geral, outras periferias se instalam, como os corpos religiosos negros e indígenas. O corpo sensual, expulso ou domesticado nas relações cotidianas institucionais, também se faz ver.

Neves (2011), ao descrever sua experiência com o funk, em uma turma de 5. ${ }^{\circ}$ ano, aponta para problematizações em torno de o funk ser negro e proibido, ainda que apareça num contexto da cultura negra musical religiosa. Durante o trabalho, um MC é convidado e duas alunas de outra turma e nacionalidade aproximam-se das aulas e falam de suas experiências com o funk em seu país. Nas discussões, o autor menciona que os/as alunos/as, ao diferenciarem os funks acessados, indicam que as letras falam de sexo, violência, poder da mulher, e apontam também diferenças na forma de dançar, tais como passos de agachar e rebolar, frevo e $p s y$. Os corpos negros, masculinos, femininos são dados a ver nas superfícies que vão se sobrepondo como corpos/conhecimento.

Martins (2009), ao tematizar o hip-hop, depara-se com uma problematização até então não identificada. Apesar de a dança em geral ser considerada predominantemente feminina, e, por isso, encontrar resistência em muitos alunos, como apontado por Santos (2013), quando da tematização do balé, a autora relata que os meninos indicavam que o break (a dança do hip-hop) não era para meninas. De sua posição de subalternidade, talvez pela feminilidade relacionada, o balé friccionava outras formas e tipos de poder em comparação com o hip-hop, que contextualmente se constitui em ambientes mais masculinizados.

Desta feita, a periferia do "feminino" (ser dança) reinstalou o "masculino" (a dança no biph-bop ser realizada principalmente por homens), e a dança de mulheres tornou-se novamente periferia. $\mathrm{Na}$ 
produção desse movimento de idas e vindas, a professora desestabilizou mais uma vez ao dar a ver a presença de $b$-girls ${ }^{11}$ no hip-hop e o projeto seguiu.

Nascimento (2013), numa tematização mais breve das danças do hiph-hop, com uma turma de $8 .^{\circ}$ ano, entreteceu outras descontinuidades ao tema. Ao iniciar o debate sobre os grupos e músicas de rap, propostos pelos/as alunos/as, a professora discorre sobre como procurou desconstruir uma ideia de essencialidade presente na discussão, ao fazer emergir a provisoriedade e a transformação constantes das propostas artísticas do hip-hop, considerando as necessidades e os lugares de fala das periferias urbanas.

Entre o movimento do feminino ao masculino que retorna ao feminino de Martins (2009) e as camadas de transitoriedade propostas por Nascimento (2013), o hip-hop, suas danças e os corpos/conhecimento vão se tecendo no currículo cultural.

Por fim, temos Portapila (2013) e Quaresma (2015) tematizando o sertanejo, e das experiências relatadas destacamos como ambos introduzem mais superfícies aos corpos ao levantarem a questão rural que se torna urbana, ou do caipira ao sertanejo, na apresentação de vídeos sobre a migração para as grandes cidades das famílias dos cantores sertanejos, ou sobre as classificações das músicas, na transitoriedade das produções acessadas ao se tornarem produtos comercializáveis por intermédio da indústria do entretenimento (PORTAPILA, 2013), à problematização da visão da mulher e das cenas lésbicas, trans, bichas, numa prevaricação invertida entre os/as autores/as/professores/as que trocam materiais a serem apresentados aos estudantes, as músicas e os clipes da dupla “As bofinhas”. Dos corpos trans produzidos em sala de aula com os alunos e alunas exalam os corpos multiplicidades do currículo cultural.

Aqui ilustramos a pragmática (semiótica e política) de inúmeros encontros. Professores/as e alunos/as e danças e corpos, o "caldo engrossado" pelas atividades pedagógicas. Nessa perspectiva, a vontade de multiplicar aciona o movimento desejado de ampliar e aprofundar os conhecimentos sobre as danças. Vimos que os professores e professoras não apenas adensam os conhecimentos a respeito da temática da dança selecionada, mas também oportunizam diferentes vozes a produzirem outras danças e corpos, distinguindo-se das perspectivas não crítica e crítica da Educação Física que, como se sabe, operam prioritariamente com os significados estabelecidos pela cultura dominante. A primeira com o intuito de fixá-la, enquanto a segunda, de criticá-la, desvelando a atuação da ideologia capitalista na sua produção e disseminação.

Observamos que no trato pedagógico camadas de significação são escavadas em diferentes sentidos: aprofundando, como um movimento "para baixo", inspirado na arqueologia, e ampliando, trazendo significações que estavam "ao lado", sentido próprio da genealogia, ambos de inspiração foucaultiana.

${ }^{11}$ Breaking-girls. Tradução livre: dançarinas de break. 
Foucault (1996) concebe a arqueologia como um método próprio de investigação e análise exaustiva dos documentos de época em busca de regras do pensamento e suas limitações e a genealogia como um método de estudo em que analisa a transformação dos conceitos, suas origens e modos como se modificam. Para o filósofo francês, cada momento histórico produz o seu conjunto de verdades e falsidades que se materializam nos discursos e nas relações sociais.

A crítica analisa os processos de rarefação, mas também de reagrupamento e de unificação dos discursos; a genealogia estuda sua formação ao mesmo tempo dispersa, descontínua e regular. $\mathrm{Na}$ verdade, estas duas tarefas não são nunca inteiramente separáveis; não há, de um lado, as formas da rejeição, da exclusão, do reagrupamento ou da atribuição; e, de outro, em nível mais profundo, o surgimento espontâneo dos discursos (FOUCAULT, 1996, p. 65).

Ao expor certas camadas, trazer problemáticas, fazer sentir "o que aquilo (corpo) pode", pensamos que "pode" ser uma produção chamada rizomática, ${ }^{12}$ ou seja, um conhecimento que vai sendo tecido como uma teia, uma rede, complexa, amplamente conectada, mas sem um eixo específico, como processo e intervenção, com o duplo: compartilhar significações e produzir novas (outras) significações daquilo que está sendo tematizado.

A visão rizomática não estabelece começo nem fim para o processo de conhecer. A multiplicidade surge como linhas independentes que representam dimensões, modos inventados de construir realidades que podem ser desconstruídos, desterritorializados. Para Deleuze e Guattari (1995b), um rizoma se pauta pelos princípios de conexão e heterogeneidade, ou seja, os pontos de um rizoma podem e devem se conectar a quaisquer outros pontos. As coisas se relacionam. Pensar é estabelecer relações com múltiplos elementos e em diversos aspectos. A análise cria conexões, ligações, pontes de comunicação, evidencia qualidades, define ângulos de abordagem, institui olhares, sempre diferentes de outros.

Percebe-se, portanto, que os trabalhos realizados com o currículo cultural não se trata de projetos, com planejamento, procedimentos, estratégias, objetivos, finalidades, algo com início, meio e fim. Ao contrário, pensamos enquanto experiência, conforme proposto por Bonetto (2017), para o currículo cultural, em que, conforme observamos em todos os relatos analisados, o meio, o efeito, a experiência (dos corpos que dançam) valem mais do que qualquer conhecimento reproduzido.

\section{Intensificar entre os tambores e os alto-falantes}

Em quase todos os relatos lidos, a música apareceu centralmente posicionada, uma vez que muitas das danças foram escolhidas a partir da observação da cultura musical dos/as estudantes que invadia a escola. Martins (2009) e Nascimento (2013) na tematização do hiph-hop; Aguiar (2009) com a música eletrônica do Psy; Portapila (2013) e Quaresma (2015), quando retratam as experiências com o sertanejo; Martins (2013), com as danças do Brasil; e Santos Júnior (2015) e Neves (2011), no funk, narram

\footnotetext{
${ }^{12} \mathrm{O}$ que remete ao conceito de rizoma, muito presente na filosofia de Gilles Deleuze e Félix Guattari. Em termos gerais, indica um tipo de pensamento que se conecta (tal como a raiz de algumas plantas) em várias direções e sem um eixo direcional. Educação em Revista | Belo Horizonte|v.36|e219772|2020
} 
experiências de tematização a partir da música e da cultura juvenil. Os demais relatos - Fogaça (2014), Colombero (2014) com o samba; Joaquim (2016) e Neves (2017) na tematização do maracatu; e Santos Júnior (2015) e Neves (2015) com as experiências com o frevo -, embora não tenham partido das músicas, tiveram na problematização das letras e nas características rítmicas do samba ou os toques do maracatu como exemplos, bem como na exploração dos instrumentos e das sonoridades deles um papel relevante no desenvolvimento das tematizações.

Apenas Santos (2013), ao tematizar o balé, não evidenciou a música. O balé, como dança teatral moderna, caracteriza-se como uma dança que não quer estar a serviço da música, ainda que se acompanhe dela, mas quis se fazer valer como uma arte independente que falasse das paixões humanas, como clamava Jean Georges Noverre, coreógrafo do século XVIII, criador do balé de ação que propunha que a dança deveria ter ação dramática própria, e não servir apenas de divertissement, papel a ela atribuído nas apresentações das óperas. Como afirma Monteiro (2006), ao analisar o papel da música e dos sentimentos no balé de ação, para Noverre:

A música, a menos material das artes, faz a ponte entre a dança e o conteúdo do poema. As
danças bourrées, gigues e gavottes, entre outras, estiveram imbricadas com a música, mas neste caso
era a dança que emprestava corporeidade à música, enquanto agora é a música que torna voláteis
os elementos do balé, tornando-os expressão de algo aéreo: o sentimento (MONTEIRO, 2006,
p. 99).

Ora, ao aproximar-se da música para que ela possa ser o poema a ser dançado, num processo de expressão da verossimilhança humana, dançar as suas paixões, inverte-se a relação que a dança anteriormente estabelecia com a música, de acompanhá-la na execução virtuosa e até acrobática de movimentos, no balé, ou nas danças de corte mencionadas, os bourrés, as gigues e as gavottes. Assim, no caminho da autonomia da dança como arte, com a ação dramática a tratar dos sentimentos humanos, a música vai deixando de ser o suporte rítmico para os saltos, giros e gestos para ter o papel mediador de ser o poema ou o texto para a dança.

Nesse traçado, a total desvinculação entre a dança e a música, como arte autônoma e moderna, no mundo ocidental, dar-se-á, no século XX, com a dança de expressão, capitaneada pela dança-teatro de Rudolf Laban. Para Laban (1978), a dança não pode estar submetida à música, propondo danças criadas, compostas e realizadas a partir da combinação de corpo, ações, espaço, dinâmica e relação. ${ }^{13} \mathrm{~A}$ música aqui não tem centralidade, ainda que possa estar presente. Esse processo será explorado de forma diferenciada nos trabalhos de um coreógrafo americano dos anos 40 do século passado, Merce Cunnigham. Para ele, todas as formas artísticas presentes num espetáculo de dança, música, artes visuais e dança deveriam ser criações autônomas e com vida própria. Como proposta compositiva, inovadora e

\footnotetext{
${ }^{13}$ No livro Domínio do movimento, Laban (1978, p. 55-56) questiona: que parte do corpo move? Em que direção? Com que velocidade? E com que grau de energia muscular? A partir dá, tece todo um estudo do movimento que apontará, posteriormente, a sitematizadas do ensino da dança em torno de cinco fundamentos: Quem dança? O corpo; O que dança? As ações; Onde dança? O espaço; Como dança? A dinâmica; Com quem dança? A relação (GOUCH, 1993).

Educação em Revista | Belo Horizonte|v.36|e219772|2020
} 
inusitada, Cunningham solicitava aos seus parceiros de criação, sobretudo John Cage, na música, e artistas visuais como Rauschenberg, que criassem os elementos sonoros e visuais do espetáculo em separado e apenas no dia da apresentação/estreia todos os elementos seriam conhecidos e performados conjuntamente (música, dança, figurino e cenografia). Atualmente, música e dança encontram-se e distendem-se em composições artísticas diversas, difusas, multifacetadas nos palcos da dança, na confirmação da coexistência de ambas como arte.

Por outro lado, na maioria dos relatos cartografados (SANTOS JÚNIOR, 2015; SANTOS, 2013; MARTINS, 2009, 2013; AGUIAR, 2009; NEVES, 2011, 2015, 2017; QUARESMA, 2015; PORTAPILA, 2013; NASCIMENTO, 2013; AGUIAR, 2009), entre os tambores, os smartphones e os alto-falantes, vibram os corpos da juventude ou da maturidade, produzindo corpos/conhecimentos ancestrais, religiosos, negros, proibidos, marginais, urbanos, rurais, pops, divertidos, num agenciamento que não intervém na autonomia da dança e da música. Contrariamente, intensifica-a na coimplicação "dançamúsica”, como dança, música, religião, ética, estética e política, no rufar retumbante de um naipe de tambores, caixas, alfaias e outros, ou no volume exasperado dos fones individuais ou dos alto-falantes pequenos, médios e grandes, negros ou coloridos, como aqueles que recebem os visitantes em cidades ribeirinhas do Norte, ou nos bares de reggae do Maranhão e da Bahia, ou nos bailes funk das periferias do Rio de Janeiro e de São Paulo, nos atualmente pequenos alto-falantes dos poetas dançantes dos metrôs das grandes cidades brasileiras. Na excitabilidade dos sons, a dança atravessa os corpos numa gestualidade conhecida, reproduzida, executada, enfim, produzida a partir de referências visuais, sobretudo veiculadas pelas mídias digitais ou por pessoas de referência.

Se do século XVIII em diante a dança agia para se autonomizar como arte dos sentimentos humanos (brancos e burgueses), desinteressada e moderna, nos salões da nobreza francesa e nos palcos dos teatros europeus, hoje, nas salas de aula, palco dos relatos investigados, há a vontade de intensificar danças atuais e corpos virtuais no contemporaneamente humano das nossas instabilidades, iniquidades e aberrações, pois, como postula Craia (2009), na análise da ontologia que aqui nos interessa, a deleuziana, a diferença-ser é diferença de intensidade, portanto ser em constante exercício de vir a ser, virtualidade.

\section{CONSIDERAÇÕES FINAIS}

Os relatos produziram, em cascata, corpos comunitários, periféricos, ancestrais, urbanos, nordestinos, rurais, negros, brancos, pardos, amarelos, trans, masculinos, femininos no desfazimento de seus próprios corpos/conhecimentos/conteúdos ou na possibilidade de serem corpos tran(sitórios), virtuais na medida em que se deixam minorar ${ }^{14}$ quando falam em público, ainda que sejam tímidos, leem

\footnotetext{
${ }^{14}$ Minorar no sentido que lhe atribuem Deleuze e Guattari (2003), como numa literatura menor. Os autores demonstram como Kafka não instala heróis ou personagens de grandes feitos, optando por dessubjetivar o sujeito (Joseph K. ou somente K.), na criação de duplos, e ainda há os juízes, os médicos, os advogados, com nomes próprios e sem nomes próprios. Os personagens se diluem nas ações e as obras ficam inacabadas. Esses procedimentos proporcionam a instalação de uma Educação em Revista | Belo Horizonte|v.36|e219772|2020
} 
textos que não conheciam, riem dos colegas e de si mesmos, calam-se para ver o outro apresentar, observam os instrumentos e as vestes, ouvem músicas, assistem a vídeos, imitam movimentos, compõem coreografias, ensaiam apresentações orais, veem espetáculos, ouvem relatos de pessoas da comunidade escolar de dentro e de fora.

A cartografia proposta não demonstrou, verificou, compreendeu ou categorizou os corpos das danças no currículo cultural, e sim mapeou territórios e linhas de força que se instalam como ações de políticas públicas, atravessadas por personagens comunitários (des)continuadores e extensores da paisagem curricular culturalmente orientada; ativou os procedimentos e os princípios ético-políticos do currículo cultural, flexibilizando-os para romper com a lógica arbórea de conhecimento-aprendizagem e multiplicar-se em movimentos de arqueologia-genealogia-rizoma-efeitos no currículo cultural, e assim produzir a experiência; e dilatou as partículas ancestrais dos corpos e das danças que pulsam nos decibéis dos tambores e dos alto-falantes no currículo cultural.

Vale salientar ainda que compor, multiplicar e intensificar não são procedimentos que ilustram categorias ontológicas do currículo cultural produzidos nas escolas, mas são vontades mapeadas nas experiências pedagógicas com as danças relatadas. Essas vontades movem os corpos das danças no currículo cultural como corpos interventivos, menores, desestabilizadores, intervalares, virtuais e relacionais que se afastam da fenomenologia encarnada muito discutida na Educação Física no Brasil, para produzir uma linguagem corporal pragmática e política. Um corpomídia? (KATZ; GREINER, 2008.)

\section{REFERÊNCIAS}

ALMEIDA, F. Q.; BRACHT, V.; GHIDETTI, F. F. A presença da fenomenologia na Educação Física brasileira: implicações para o estudo do corpo e outras problematizações. Educación Física y Ciencia, Buenos Aires, $\quad$ v. 15, n. 2, 2013. Disponível em: http://www.scielo.org.ar/pdf/efyc/v15n2/v15n2a01.pdf. Acesso em: 21 maio 2018.

BETTI, M. Corpo, motricidade e cultura: a fundação pedagógica da educação física sob uma perspectiva fenomenológica e semiótica. Relatório de Pesquisa apresentado ao Departamento de Educação física da Faculdade de Ciências da Unesp. Bauru, 2006.

BONETTO, P. X. R. A escrita-currículo da perspectiva cultural de Educação Física: entre aproximações, diferenciações, laissez-faire e fórmula. 2016. 250 f. Dissertação (Mestrado em Educação) Universidade de São Paulo, São Paulo, 2016.

BONETTO, P. X. R. A escrita-currículo da perspectiva cultural da Educação Física: por que fazemos o que fazemos? Texto não publicado. 2017. Disponível em: http://www.gpef.fe.usp.br/teses/bonetto_03.pdf. Acesso em: 23 mar. 2017.

BRACHT, V. Cultura corporal, cultura de movimento ou cultura corporal de movimento? In: SOUZA JÚNIOR, M. (org.). Educação Física escolar: teoria e política curricular, saberes escolares e proposta

literatura menor, o gaguejar dentro da própria língua, porque aberta a outros e outros sentidos, na medida em que não se cristalizam nas narrativas. 
pedagógica. 2. ed. Recife: Edupe, 2011.

COSTA, L. M.; NEIRA, M. G. A educação corporal. In: NEIRA, M. G. Educação Física cultural. São Paulo: Blucher, 2016. p. 31-47.

CRAIA, E. O VIRTUAL: destino da ontologia de Gilles Deleuze. Revista de Filosofia Aurora, Curitiba, v. 21, n. 28, p. 107-123, jan./jun. 2009.

DELEUZE, G.; GUATTARI, F. Introdução: rizoma. Mil platôs: capitalismo e esquizofrenia. Rio de Janeiro: Ed. 34, 1995a. v. 1, p. 10-27.

DELEUZE, G.; GUATARI, F. 20 de novembro de 1923: postulados da linguística. Mil platôs: capitalismo e esquizofrenia. Rio de Janeiro: Ed. 34, 1995b. v. 2, p. 11-49.

DELEUZE, G.; GUATTARI, F. Kafka: para uma literatura menor. Lisboa: Assírio \& Alvim, 2003.

DELEUZE, G.; GUATTARI, F. 1933: micropolítica e segmentariedade. Mil platôs: capitalismo e esquizofrenia. Rio de Janeiro: Ed. 34, 1996. v. 1, p. 76-106.

FOUCAULT, M. A ordem do discurso. 3. ed. São Paulo: Loyola, 1996.

FREIRE, J. B. Educação de corpo inteiro. São Paulo: Scipione, 1989.

GEHRES, A. F.; NEIRA, M. G. Linguagem e Educação Física: algumas considerações sobre o currículo cultural. Revista Brasileira de Educação Física Escolar, Curitiba, ano V, v. 3, p. 30-46, mar. 2020.

GOUGH, M. In touch with dance. Lancaster: Whitethorn Books, 1993.

GREINER, C. O corpo: pistas para estudos indisciplinares. 3. ed. São Paulo: Annablume, 2008.

GREINER, C. O corpo em crise: novas pistas e o curto-circuito das representações. São Paulo: Annablume, 2010.

GUEDES, D. P. Exercício físico na promoção da saúde. Londrina: Midiograf, 1995.

KATZ, H.; GREINER, C. Por uma teoria do corpo-mídia. In: GREINER, Christine. O corpo: pistas para estudos indisciplinares. 3. ed. São Paulo: Annablume, 2008. p. 125-134.

KUNZ, E. Transformação didático-pedagógica do esporte. Ijuí: Unijuí, 1994.

LABAN, R. Domínio do movimento. São Paulo: Summus, 1978.

LOPES, A. C. Teorias pós-críticas, política e currículo. Educação Sociedade \& Culturas, Porto, n. 39, p. 7-23, 2013. Disponível em: https://www.fpce.up.pt/ciie/sites/default/files/02.AliceLopes.pdf. Acesso em: 8 jul. 2017.

MONTEIRO, M. Noverre: cartas sobre a dança. São Paulo: Editora da Universidade de São Paulo; Fapesp, 2006.

NEIRA, M. G. Educação Física. São Paulo: Blucher, 2011.

NEIRA, M. G. O currículo cultural da Educação Física: por uma pedagogia da(s) diferença(s). In: NEIRA, M. G.; NUNES, M. L. F. (org.). Educação Física cultural: por uma pedagogia da(s) diferença(s). Curitiba: CRV, 2016. p. 67-105.

NEIRA, M. G. O currículo cultural da Educação Física: pressupostos, princípios e orientações didáticas. Revista e-Curriculum, São Paulo, v. 16, n. 1, p. 4-28, jan./mar. 2018.

NEIRA, M. G. Educação Física cultural: inspiração e prática pedagógica. 2. ed. Jundiaí: Paco, 2019. Disponível em: http://www.gpef.fe.usp.br/teses/marcos 41.pdf. Acesso em: 10 abr. 2020. 
NEIRA, M. G.; NUNES, M. L. F. Pedagogia da cultura corporal: crítica e alternativas. São Paulo: Phorte, 2006.

NEIRA, M. G.; NUNES, M. L. F. Educação Física, currículo e cultura. São Paulo: Phorte, 2009.

NEIRA, M. G.; NUNES, M. L. F. Contribuições dos estudos culturais para a Educação Física. Revista Brasileira de Ciências do Esporte, Florianópolis, v. 33, n. 3, p. 671-685, jul./set. 2011. Disponível em: http://www.scielo.br/scielo.php?script=sci_arttext\&pid=S0101-32892011000300010. Acesso em: 23 set. 2016.

ROMAGNOLI, R. C. O conceito de implicação e a pesquisa-intervenção institucionalista. Psicologia \&

Sociedade, Belo Horizonte, v. 26, n. 1, p. 44-52, 2014. Disponível em: http://www.ufrgs.br/seerpsicsoc/ojs2/index.php/seerpsicsoc/article/view/3696/2312. Acesso em: 25 mar. 2016.

SAVIANI, D. Escola e democracia: teorias da educação, curvatura da vara, onze teses sobre educação e política. São Paulo: Cortez, 1983.

SOARES, C. L. et al. Metodologia do ensino de Educação Física. São Paulo: Cortez, 1992.

TANI, G. et al. Educação Física escolar: uma abordagem desenvolvimentista. São Paulo: EPU, 1988.

\section{RELATOS DE EXPERIÊNCIA}

AGUIAR, C. S. Danças eletrônicas: do intervalo as aulas de Educação Física. EMEFM Derville Alegretti. São Paulo, SP, 2009. Disponível em: http://www.gpef.fe.usp.br/teses/camila 01.pdf. Acesso em: 2 maio 2020 .

COLOMBERO, R. M. M. P. Samba: do corpo dominado pela chibata à alegria da alma. EMEF Ministro Synésio Rocha. São Paulo, SP, 2014. Disponível em: http://www.gpef.fe.usp.br/teses/colombero 01.pdf. Acesso em: 2 maio 2020.

FOGAÇA, M. Samba: um elemento de resistência no espaço entre identidades culturais. Colégio Marista Arquidiocesano, São Paulo, SP, 2014. Disponível em: http://www.gpef.fe.usp.br/teses/Relato\%20Monica\%20Fogaca Samba.pdf. Acesso em: 2 maio 2020.

JOAQUIM, M. O. X. Maracatu: o som da nação. E.E. Prof. Anthenor Fruet, Itu, SP, 2016. Disponível em:

http://www.gpef.fe.usp.br/semef2016/visemef arquivos/Textos $\% 20$ completos/mariana xavier.pdf. Acesso em: 2 maio 2020.

LIMA, M. F. O funk na ETEC JRM. Escola Técnica José Rocha Mendes. São Paulo, SP, 2016. Disponível em: http://www.gpef.fe.usp.br/teses/marcelo ferreira 01. Acesso em: 2 maio 2020.

MARTINS, J. C. J. Hiph-hop na escola. EMEF Tenente Alípio Andrada Serpa. São Paulo, SP, 2009. Disponível em: http://www.gpef.fe.usp.br/teses/jacque 03.pdf. Acesso em: 2 maio 2020.

MARTINS, J. C. J. Dançando pelo Brasil. E. E. Alcides da Costa Vidigal. São Paulo, SP, 2013. Disponível em: http://www.gpef.fe.usp.br/teses/relato danca jacque.pdf. Acesso em: 2 maio 2020.

NASCIMENTO, A. S. Tematizando o rap na escola: dias de luta ou dias de glória? São Paulo, SP, 2013. Disponível em: http://www.gpef.fe.usp.br/teses/aline 01.pdf. Acesso em: 2 maio 2020.

NEVES, M. R. das. Tematizando o funk nas aulas de Educação Física escolar. EMEF Dom Pedro I. São Paulo, SP, 2011. Disponível em: http://www.gpef.fe.usp.br/teses/marcos ribeiro 03.pdf. Acesso em: 2 maio 2020.

NEVES, M. R. Frevo. EMEF Dom Pedro I. São Paulo, SP, 2015. Disponível em: http://www.gpef.fe.usp.br/teses/marcos ribeiro 06.pdf. Acesso em: 2 maio 2020. 
NEVES, M. R. O maracatu nas aulas de Educação Física: exu, macumba e outras significações, o sangue de Jesus tem poder! CIEJA Campo Limpo, São Paulo, SP, 2017. Disponível em: http://www.gpef.fe.usp.br/teses/marcos ribeiro 08.pdf. Acesso em: 2 maio 2020.

PORTAPILA, D. M. O. Trilhando o ritmo sertanejo. E. E. Samuel Klabin. São Paulo, SP, 2013 Disponível

em: http://www.gpef.fe.usp.br/semef2016/visemef arquivos/Textos $\% 20$ completos/dayane.pdf. Acesso em: 2 maio 2020.

QUARESMA, F. N. Sertanejo: sofrência entre xs muitx elxs. E. E. Maria Peciole Gianasi. São Paulo, SP, $2015 . \quad$ Disponível em: http://www.gpef.fe.usp.br/semef2016/visemef arquivos/Textos $\% 20$ completos/felipe.pdf. Acesso em: 2 maio 2020.

SANTOS JÚNIOR, F. N. Entre gingas e tramelas: a cultura negra no currículo escolar. EMEF Maria Rita de Cássia Pinheiro Simões Braga. São Paulo, SP, 2015. Disponível em: http://www.gpef.fe.usp.br/semef2016/visemef arquivos/Textos $\% 20$ completos/flavio.pdf. Acesso em: 2 maio 2020.

SANTOS, L. A. O balé nas aulas de Educação Física na rede estadual de ensino. E. E. Pastor João Nunes. São Paulo, 2013. Disponível em: http://www.gpef.fe.usp.br/teses/Relato $\% 20$ Luiz $\% 20$ Alberto $\% 20 \mathrm{dos} \% 20$ Santos $\% 20 \mathrm{Bale} \% 20$ nas $\% 20 \mathrm{a}$ ulas.pdf. Acesso em: 2 maio 2020.

Submetido: $11 / 02 / 2019$

Aprovado: 06/05/2020

\section{ERRATA}

DOI: http://dx.doi.org/10.1590/0102-4698219772er

Para o artigo publicado como:

GEHRES, ADRIANA DE FARIA, BONETTO, PEDRO XAVIER RUSSO, \& NEIRA, MARCOS GRACIA. (2020). OS CORPOS DAS DANÇAS NO CURRÍCULO CULTURAL DE EDUCAÇÃO FÍSICA. Educação em Revista, 36, e219772. Epub August 14, 2020.https://dx.doi.org/10.1590/0102-4698219772

Na identificação dos autores,

\section{Onde se lê:}

Marcos Gracia Neira

\section{Leia-se:}

Marcos Garcia Neira 